\title{
Nutcracker syndrome - a mini review on current knowledge
}

\author{
Jakub Tomasz Kramek \\ Department of Vascular and Endovascular Surgery, Angiology \\ and Phlebology, Poznan University of Medical Sciences, \\ Poland; University Hospital of Lord's Transfiguration, \\ Poznan University of Medical Sciences, Poland \\ (iD) https://orcid.org/0000-0003-1968-6893 \\ Corresponding author: jakub_kramek@onet.eu \\ Zbigniew Krasiński \\ Department of Vascular and Endovascular Surgery, Angiology \\ and Phlebology, Poznan University of Medical Sciences, \\ Poland; University Hospital of Lord's Transfiguration, \\ Poznan University of Medical Sciences, Poland \\ (iD) https://orcid.org/0000-0003-3600-8680

\section{Hubert Stępak} \\ Department of Vascular and Endovascular Surgery, Angiology \\ and Phlebology, Poznan University of Medical Sciences, \\ Poland; University Hospital of Lord's Transfiguration, \\ Poznan University of Medical Sciences, Poland \\ iD https://orcid.org/0000-0003-3600-8680
}

DOI: https://doi.org/10.20883/medical.e527

Keywords: nutcracker syndrome, venous compression syndrome, pelvic congestion syndrome, venous reflux, idiopathic haematuria

Published: 2021-09-22

How to Cite: Kramek JT, Krasiński Z, Stępak H. Nutcracker syndrome - a mini review on current knowledge. Journal of Medical Science. 2021 Sep. 22;90(3):e527. doi:10.20883/ medical.e527

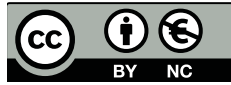

(C) 2021 by the author(s). This is an open access article distributed under the terms and conditions of the Creative Commons Attribution (CC BY-NC) licencse. Published by Poznan University of Medical Sciences

\section{ABSTRACT}

The Nutcracker Syndrome (NCS) constitutes an underdiagnosed condition defined as an external compression of the left renal vein, with a consequent blood outflow impairment. The majority of cases involve left renal vein entrapment between the abdominal aorta and the superior mesenteric artery. The exact epidemiology is unknown, due to the lack of consensus with regard to the diagnostic criteria, and the frequently asymptomatic course of the disease. NCS may occur at any age, with a peak presentation in the second and third decade of life, as well as with a slight prevalence in female patients. The most frequent presentations include micro and macroscopic haematuria, orthostatic proteinuria, orthostatic hypotension, flank pain. In addition, patients may develop pelvic congestion syndrome comprising dyspareunia, dysmenorrhea, abdominal pain, pelvic, gluteal, vulvar varicose veins and varicocele in men. The clinical suspicion of NCS, based on signs and symptoms, requires imaging confirmation involving such modalities as Doppler ultrasonography, computed tomography and magnetic resonance angiography, intravascular ultrasound and phlebography. Treatment options of NCS range from the conservative follow-up to nephrectomy, therefore, an appropriate approach should be based on clinical manifestations and the severity of symptoms. Patients presenting with mild to moderate haematuria and with other acceptable symptoms should be treated conservatively. In cases of severe symptoms, or when conservative management fails, invasive treatment should be considered. The recommended open surgical procedures include left renal vein distal transposition and renal autotransplantation. Additionally, the endovascular stenting approach seems encouraging, although due to uncertain mid and long term consequences this treatment option should be reserved for patients unsuitable for open surgery, or after a failed open surgical approach. Further long term follow-up is required to develop objective treatment guidelines. 


\section{Introduction}

The Nutcracker Phenomenon (NCP), defined as the external compression of the left renal vein (LRV) and a consequent blood outflow impairment, was first described by Grant in 1937. The term "Nutcracker Syndrome" (NCS) is reserved for the symptomatic patients suffering from NCP [2]

The majority of cases involve left renal vein (LRV) entrapment between the abdominal aorta and the superior mesenteric artery (SMA) - anterior NCP. Posterior NCP describes the compression of LRV between the aorta and the vertebral column [3]. This rare anomaly may occur when LRV passes behind the aorta. Moreover, NCP also includes other rare aetiologies of LRV compression, such as tumours, lordosis, or LRV stretching over the aorta [4]. The exact epidemiology is unknown due to lack of consensus with regard to the diagnostic criteria and the frequently asymptomatic course of the disease. NCS may occur at any age, with a peak presentation in the second and third decade of life, as well as a slight prevalence in women [5]. There are reports suggesting that an asthenic body type with a decreased volume of retroperitoneal fat tissue, particularly in tall patients, may contribute to the development of NCS [6-8], which stems from the narrowing of the angle created by the aorta and SMA.

\section{Clinical presentation}

Numerous NCS cases remain asymptomatic. The most frequent presentations include microscopic haematuria (8.6-21.7\%), as well as macroscopic haematuria $(39.1-69.5 \%)$, proteinuria $(4.3-26.1 \%)$, orthostatic hypotension, and flank pain (43.4$65.2 \%$ ). Furthermore, patients may develop pelvic congestion syndrome (PCS) comprising dyspareunia, dysmenorrhea, abdominal pain, pelvic, gluteal, vulvar varicose veins and varicocele in men $(8.7-21.7 \%)[4-6,9]$. The abovementioned conditions result from venous reflux, and elevated venous pressure [10], which may contribute to the creation and recurrence of lower extremity varices. The underlying mechanism of the haematuria is the distension of small veins of the renal fornix which rupture into the collecting calyces [11]. Consequently, impaired renal haemodynamics may lead to an increase in norepineph- rine and angiotensin II levels, which presumably are the cause of proteinuria [12]

\section{Diagnosis}

In order to confirm the suspected NCS on the basis of clinical signs and symptoms, the presence of haematuria should be determined [13]. Positive laboratory result requires imaging confirmation with Doppler ultrasonography (DUS) (sensitivity: 69-90\%, specificity: 89-100\%) [14], computed tomography (CT), as well as magnetic resonance (MR) angiography, intravascular ultrasound (IVUS) (specificity of 90\%) [14] and phlebography $[6,7,15]$. DUS constitutes the first line examination, the diagnostic value of which may be further enhanced by the calculating of the peak velocity (PV) ratio between the compressed segment of LRV at the hilar portion, the measurement of the angle between SMA and the aorta, as well as LRV diameter at the hilar portion [16]. Results of PV ratio exceeding 5 may suggest NCS [15]. Additionally, it is essential to perform the DUS examination in an upright position, since the SMA angle closes, haemodynamic results indicative of NCS [16]. In fact, the upright position and functional haemodynamic imaging represent the advantages of the ultrasound examination as compared to other imaging modalities. Both MR and CT may reveal LRV compression and the distention and varicosity of pelvic veins. In terms of the CT diagnostic criteria of NCS, they include "beak sign" (sensitivity: $91.7 \%$, specificity: $88.9 \%$ ), beak angle $<32$ degrees (sensitivity: $83.3 \%$, specificity: $88.9 \%$ ), LRV diameter ratio $>4.9$ (sensitivity: $66.7 \%$, specificity: 100\%) (Figure 1), and an angle between SMA and the aorta $<39$ degrees (sensitivity: $100 \%$, specificity: $55.6 \%$ ) (Figure 2) $[14,15,17]$. It is worth noting that a definitive advantage of MR is the lack of radiation exposure, which is beneficial in younger patients. Furthermore, phlebography and venous pressure gradient measurement between the distal LRV and the inferior vena cava remain the gold standard. Pressure gradient over $3 \mathrm{~mm} \mathrm{Hg}$ is significant for NCS $[4,5,15,17]$. Nevertheless, both techniques are rendered invasive, although phlebography might allow for a simultaneous endovascular intervention addressing LRV com- 


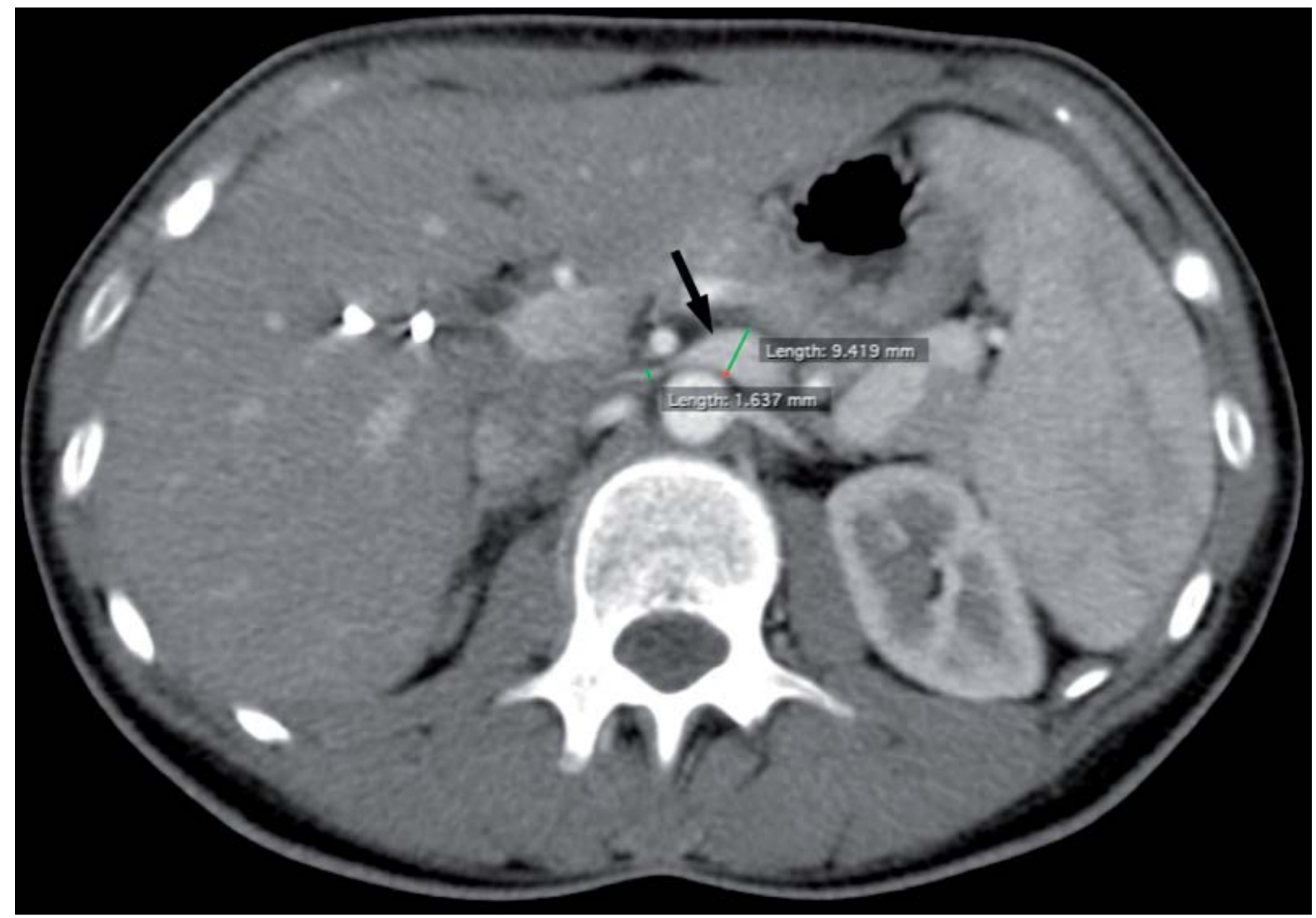

Figure 1. CT signs of NCS in a patient admitted to our department. The "beak sign" (black arrow). LRV diameter ratio exceeding $>4.9$ $(5,75$ in this patient)

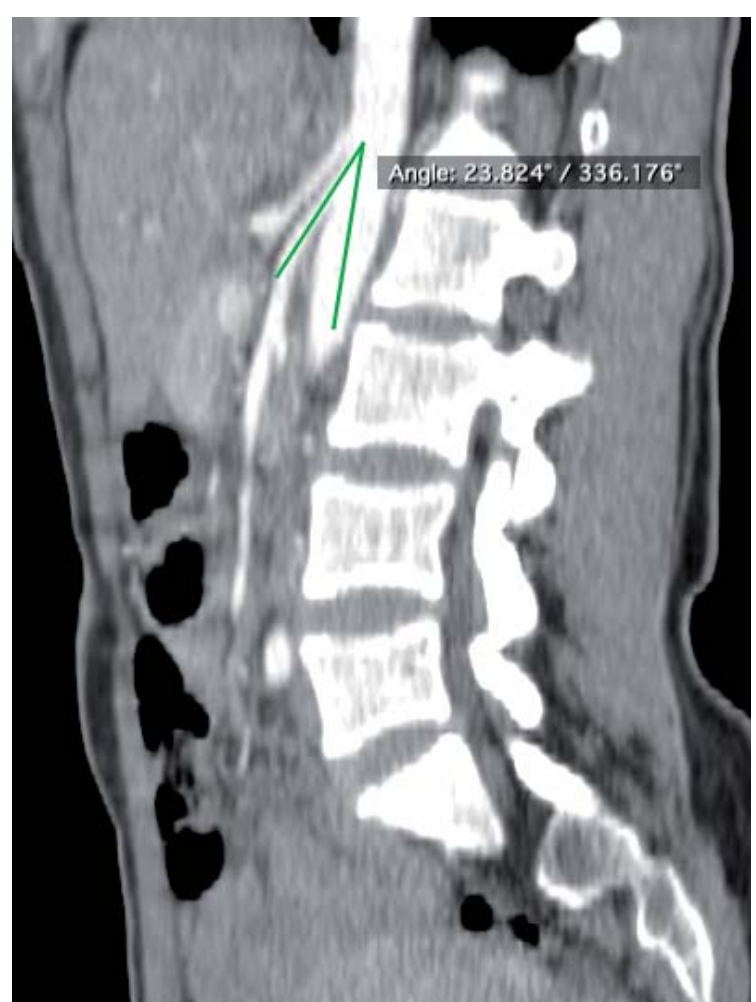

Figure 2. CT signs of NCS in a patient admitted to our department. The angle between SMA and the aorta $<39$ degrees

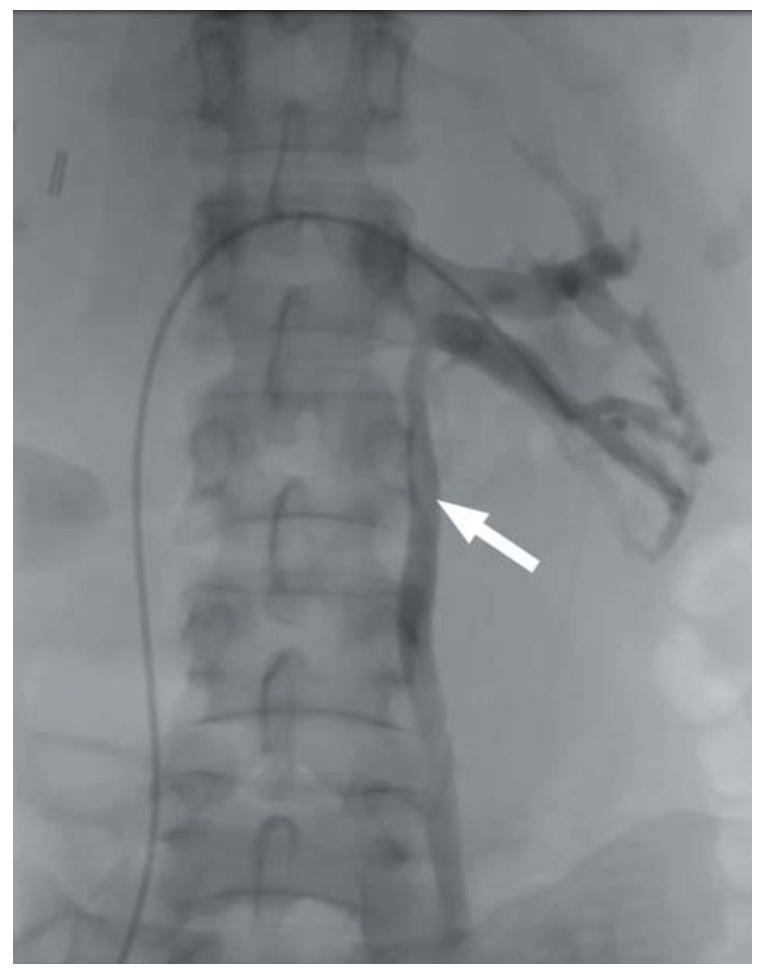

Figure 3. A patient admitted to our department (from Figures 1 and 2). Intraoperative phlebography presenting gonadal vein distention (white arrow) 
pression (Figure 3 ). Therefore, IVUS is becoming a valuable supplementary tool of the diagnostic process [17].

\section{Management}

Treatment options of NCS range from conservative follow-up to nephrectomy, thus, the appropriate approach should be based on clinical manifestations, as well as the severity of the symptoms. Patients presenting with mild to moderate haematuria and with other acceptable symptoms should be treated conservatively. Such management includes: observation, ACE inhibitors in case of orthostatic proteinuria (especially alacepril), and acetylsalicylic acid in order to enhance renal perfusion $[6,14,18]$. Furthermore, a follow-up period of at least 2 years duration is also recommended in patients under 18 years of age. According to Kurklinsky et al., in $75 \%$ of this population, a resolution of symptoms will be observed [19], which can be attributed to a physical growth leading to an increase of the retroperitoneal fat and fibrous tissue, with a consequent correction of the anatomical relationships of SMA and the aorta $[5,15]$.

In cases of severe symptoms, or when the conservative management fails, invasive treatment should be considered. The recommended open surgical procedures comprise LRV distal transposition and renal autotransplantation $[4,6$, $8,10,13,20,21]$. The aim of the transposition is the reimplantation of the LRV into the inferior vena cava (IVC) distally to the origin of SMA. In order to allow a tension free anastomosis, an additional patch or a cuff from the venous autograft might be utilised. Moreover, LRV transposition is performed by laparotomy, and requires extensive retroperitoneal dissecting, thus, it might be associated with standard open surgical complications. Renal autotransplantation is even more challenging, and entails renal excision with a simultaneous reimplantation in the iliac fossa. Alternative surgical techniques include venous bypass between either the renal or the gonadal vein and IVC $[8,21]$.The treatment may also involve renal anterior nephropexy and pelvic varicosities excision or ablation in order to address LRV stretching over aorta and pelvic congestion, respectively, resulting from the venous reflux [22]. When oth- er treatment options fail and severe haematuria reoccurs, nephrectomy might constitute the only solution $[13,23]$. Interestingly, reported outcomes of laparoscopic interventions are comparable with open surgical procedures [24].

An endovascular stenting (EVS) approach seems encouraging, although due to uncertain mid and long term consequences, this treatment option should be reserved for patients unsuitable for open surgery, or after a failed open surgical approach [25]. Chen et al. reported improvement of clinical features in $95 \%$ of patients within a 5 year follow-up period in the group of 61 patients following EVS, with only 4 cases of stent migration [26]. The procedure allows for both diagnostic phlebography and pressure gradient measurement, as well as for the simultaneous treatment. EVS can be performed with either balloon-expandable or self-expandable stents (Figure 4) [26, 27]. Nevertheless, this technique has certain limitations. The possible complications include stent dislodgement and migration into the IVC, or even

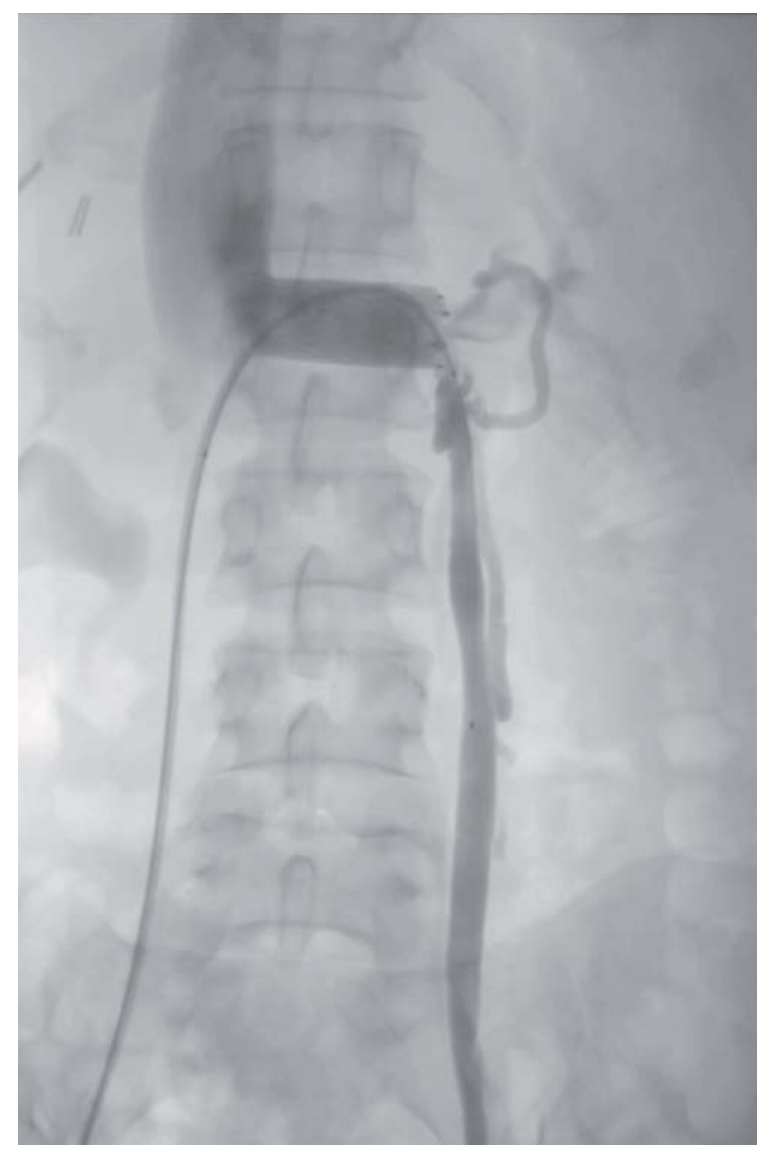

Figure 4. A patient admitted to our department (from Figures 1 and 2). Intraoperative phlebography presenting a successful stenting of LRV 
into the right atrium with the necessity of a surgical removal $[26,28]$. The stent might also displace distally into the renal hilum resulting in an occlusion. In terms of prevention of such complications, authors emphasise the importance of the adequate stent sizing [26]. Other possible complications involve stent thrombosis, fracture, or restenosis $[26,28,29]$. However, Jayaraj et al. described a hybrid approach to the treatment of NCS. According to their strategy, LRV distal transposition is followed by endovascular stent implantation and insertion of external stitches to prevent stent migration [30]. Although EVS remains less invasive, patients require anticoagulation and the administration of antiplatelet medication in the postoperative period [6].

\section{Conclusion}

NCS seems to be an underdiagnosed cause of haematuria, proteinuria and PCS. The diagnostic modalities include DUS, CT, MR and invasive techniques, such as phlebography and IVUS. The decision regarding the course of treatment should be based on the severity of the clinical presentation, with the aim of resolving the symptoms. The management is based on open vascular procedures - the transposition of LRV and renal autotransplantation, although minimally invasive strategies, e.g. laparoscopy and EVS, present promising results. Nonetheless, further long term follow-up is required to develop objective treatment guidelines.

\section{Acknowledgements}

\section{Conflict of interest statement}

The authors declare no conflict of interest.

\section{Funding sources}

There are no sources of funding to declare.

\section{References}

1. Grant J. In: Anonymous method of anatomy. Baltimore, MD: Williams and Wilkins; 1937. p. 137.

2. Shin JI, Lee JS. Nutcracker phenomenon or nutcracker syndrome [letter]? Nephrol Dial Transplant. 2005;20(9):2015.

3. Deser SB, Onem K, Demirag MK, Buyukalpelli R. Surgical treatment of posterior nutcracker syndrome presented with hyperaldosteronism. Interact Cardiovasc Thorac Surg 2016;22: 682e4.
4. Shokeir AA, el-Diasty TA, Ghoneim MA. The nutcracker syndrome: new methods of diagnosis and treatment. Br J Urol 1994;74:139e43.

5. Shin JI, Lee JS, Kim MJ. The prevalence, physical characteristics and diagnosis of nutcracker syndrome [letter]. Eur J Vasc Endovasc Surg. 2006;32(3):335-336.

6. HeY,WuZ,ChenS,TianL,LiD,LiM,JinW,ZhangH. Nutcracker syndrome-how well do we know it? Urology 2014; 83: 12-17 [PMID: 24139744]

7. OKADA M, TSUZUKI K, ITO S. Diagnosis of the nutcracker phenom- enon using two-dimensional ultrasonography. Clin Nephrol 1998; 49:35e40.

8. Sharper KRL, Jackson JE, Williams G. The nutcracker syndrome: An uncommon cause of haematuria. BJU 1994;74: 144-146.

9. Camilo A. Velasquez, Ayman Saeyeldin, Mohammad A. Zafar, Adam J. Brownstein, Young Erben,A systematic review on management of nutcracker syndrome,Journal of Vascular Surgery: Venous and Lymphatic Disorders, Volume 6, Issue 2, 2018, Pages 271-278, ISSN 2213-333X,

10. Stewart BH, Reiman G. Left renal venous hypertension "nutcracker" syndrome. Managed by direct renocaval reim- plantation. Urology 1982;20:365e9.

11. Beinart C, Sniderman KW, Saddekni S, Weiner M, Vaughan Jr ED, Sos TA. Left renal vein hypertension: a cause of occult hematuria. Radiology 1982;145:647e50.

12. Mazzoni MB, Kottanatu L, Simonetti GD, Ragazzi M, Bian- chetti MG, Fossali EF, Milani GP. Renal vein obstruction and orthostatic proteinuria: a review. Nephrol Dial Transplant 2011; 26: 562-565 [PMID: 20656752 DOI: 10.1093/ndt.gfq444]

13. Ahmed K, Sampath R, Khan MS. Current trends in the diagnosis and management of renal nutcracker syndrome: a review. Eur J Vasc Endovasc Surg 2006;31:410e6.

14. Ananthan K, Onida S, Davies AH. Nutcracker Syndrome: An Update on Current Diagnostic Criteria and Management Guidelines. Eur J Vasc Endovasc Surg. 2017 Jun;53(6):886-894. doi: 10.1016/j.ejvs.2017.02.015. Epub 2017 Mar 27. PMID: 28356209

15. Seung Hyup Kim, MD. Doppler US and CT Diagnosis of Nutcracker Syndrome. Korean J Radiol 2019;20(12):1627-1637

16. Fitoz S, Ekim M, Ozcakar ZB, Elhan AH, Yalcinkaya F. Nutcracker syndrome in children: the role of upright position examination and superior mesenteric artery angle measurement in the diagnosis. J Ultrasound Med 2007;26:573- 580

17. Kim KW, Cho JY, Kim SH, Yoon JH, Kim DS, Chung JW, et al. Diagnostic value of computed tomographic findings of nutcracker syndrome: correlation with renal venography and renocaval pressure gradients. Eur J Radiol 2011;80:648e54.

18. Ha T-S, Lee E-J. ACE inhibition in orthostatic proteinuria associated with nutcracker syndrome would be individualized [letter reply]. Pediatr Nephrol. 2007;22(5):759-760. 
19. Kurklinsky AK, Rooke TW. Nutcracker phenomenon and nutcracker syndrome. Mayo Clin Proc 2010;85:552e9.

20. Chuang $\mathrm{CK}$, Chu SH, Lai PC. The nutcracker syndrome managed by autotransplantation. J Urol 1997;157:1833e4.

21. Said SM, Gloviczki P, Kalra M, Oderich GS, Duncan $A A$, D Fleming $M$, et al. Renal nutcracker syndrome: surgical options. Semin Vasc Surg 2013;26:35e42.

22. Wendel RG, Crawford ED, Hehman KN. The "nutcracker" phenomenon: an unusual cause for renal varicosities with hematuria. J Urol 1980;123:761e3.

23. Hohenfellner $M$, Steinbach $F$, Schultz-Lampel $D$, et al. The nutcracker syndrome: new aspects of pathophysiology, diagnosis and treatment. J Urol. 1991;146(3):685-688

24. Hartung O, Azghari A, Barthelemy P, Boufı M, Alimi YS. Laparoscopic transposition of the left renal vein into the inferior vena cava for nutcracker syndrome. J Vasc Surg 2010;52:738e41.

25. Gloviczki, P., Dalsing, M.C., Eklöf, B., Lurie, F., Wakefield, T.W., \& Gloviczki, M.L. (Eds.). (2017). Handbook of Venous and Lymphatic Disorders: Guidelines of the American Venous Forum (4th ed.). CRC Press. https://doi.org/10.1201/9781315382449

26. Chen S, Zhang H, Shi H, Tian L, Jin W, Li M. Endovascular stenting for treatment of Nutcracker syndrome: report of 61 cases with long-term followup. J Urol 2011;186:570e5.

27. Neste MG, Narasimham DL, Belcher KK. Endovascular stent placement as a treatment for renal venous hypertension. J Vasc Interv Radiol. 1996;7(6):859861.

28. Rana MA, Oderich GS, Bjarnason H. Endovenous removal of dislodged left renal vein stent in a patient with nutcracker syndrome. Semin Vasc Surg 2013;26:43e7.

29. Quevedo HC, Arain SA, Abi Rafeh N. Systematic review of endovascular therapy for nutcracker syndrome and case presentation. Cardiovasc Revasc Med 2014;15:305e7.

30. Jayaraj A, Gloviczki P, Peeran S, Canton L. Hybrid intervention for treatment of the nutcracker syndrome. J Vasc Surg Cases. 2015 Nov 17;1(4):268-271. doi: 10.1016/j.jvsc.2015.08.005. PMID: 31724604; PMCID: PMC6849905. 